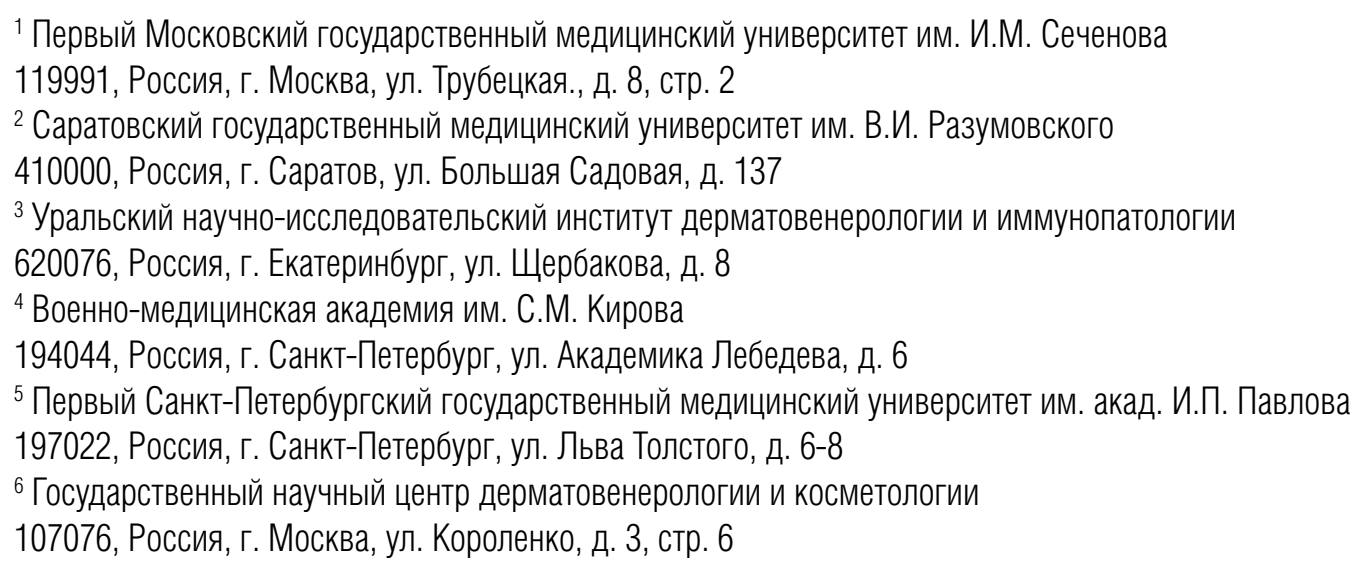

В настоящее время во всем мире используется большое количество классификаций псориаза, незначительно отличающихся друг от друга. Часть классификаций содержит формы заболевания, выделенные по описательному принципу, не имеющие в основе особенностей патогенеза. Не все дерматологи имеют общее понимание особенностей разных форм псориаза, что отражается как на процессе диагностики, так и на подходах к терапии. Авторы предлагают обновленную клиническую единую классификацию псориаза, включающую псориатический артрит, которая отражает современный взгляд на классификацию псориаза в России и в мире.

Ключевые слова: псориаз, псориатический артрит, классификация псориаза.

Конфрликт интересов: авторы данной статьи подтвердили отсутствие конфрликта интересов, о котором необходимо сообщить.

Источник финансирования: работа выполнена и опубликована за счет финансирования по месту работы авторов.

Для цитирования: Олисова О.Ю., Бакулев А.Л., Кохан М.М., Хайрутдинов В.Р., Соколовский Е.В., Хобейш М.М., Карамова А.Э. К вопросу о классификации псориаза. 2021;97(5):18-25. doi: https://doi.org/10.25208/vdv1267 


\title{
Revisiting the question of psoriasis classification
}

(C) Olga Yu. Olisova', Andrey L. Bakulev², Muza M. Kokhan³, Vladislav R. Khairutdinov4, Evgeny V. Sokolovskiy ${ }^{5}$, Marianna M. Khobeych ${ }^{5}$, Arfenya E. Karamova ${ }^{6 *}$

\author{
${ }^{1}$ Sechenov University \\ Trubetskaya str., 8, bldg 2, 119991, Moscow, Russia \\ 2 Saratov State Medical University named after V.I. Razumovsky \\ Bolshaya Sadovaya str., 137, 410000, Saratov, Russia \\ ${ }^{3}$ Ural Scientific Research Institute of Dermatovenerology and Immunopathology \\ Shcherbakova str., 8, 620076, Yekaterinburg, Russia \\ ${ }^{4}$ S.M. Kirov Military Medical Academy \\ Akademika Lebedeva str., 6, 194044, Saint Petersburg, Russia \\ ${ }^{5}$ First Pavlov State Medical University of St. Petersburg \\ Lva Tolstogo str., 6-8, 197022, Saint Petersburg, Russia \\ ${ }^{6}$ State Research Center of Dermatovenereology and Cosmetology \\ Korolenko str., 3, bldg 6, 107076, Moscow, Russia
}

Currently there are a large number of psoriasis classifications, slightly different from each other, used worldwide. Some of these classifications contain the disease forms allocated descriptively, without the pathogenesis characteristics in their basis. Among the dermatologists, there is lack of common understanding of various psoriasis forms peculiarities. And that affects both the diagnostic process and the approaches to therapy. The authors propose a revised unified clinical classification of psoriasis, including psoriatic arthritis. This method reflects the up-to-date view on the classification of psoriasis in Russia and globally.

Keywords: psoriasis, psoriatic arthritis, classification of psoriasis.

Conflict of interest: the authors of this article have confirmed that there is no conflict of interest to declare.

Source of funding: the preparation of the manuscript was carried out by the means of the author's team.

For citation: Olisova OYu, Bakulev AL, Kokhan MM, Khairutdinov VR, Sokolovskiy EV, Khobeych MM, Karamova AE. Revisiting the question of psoriasis classification. 2021;97(5):18-25. doi: https://doi.org/10.25208/vdv1267 
Псориаз - генетически детерминированное хроническое заболевание кожи мультифакториальной природы с рецидивирующим течением, обусловленное иммуноопосредованным воспалением с частым поражением опорно-двигательного аппарата. Псориаз является одним из наиболее распространенных дерматозов. По данным Всемирной организации здравоохранения, заболеваемость псориазом в мире составляет 0,5-5,5\% от общей численности населения и находится в прямой зависимости от климатогеографического региона [1]. Несмотря на характерные проявления псориаза при поражении кожи, не существует единой клинической классификации заболевания [2].

В настоящее время известно большое количество классификаций псориаза, однако они существенно не отличаются друг от друга. Наиболее часто в них выделяют следующие клинические фрормы - вульгарный псориаз, пустулезный псориаз, псориатическую эритродермию и псориатический артрит (артропатический псориаз) [3-6]. Внутри этих основных фрорм различают некоторые варианты, имеющие свои особенности: каплевидный, инверсный (интертригинозный), себорейный, ладонно-подошвенный, экссудативный как разновидности вульгарного псориаза; генерализованный пустулезный псориаз Цумбуша, ладонно-подошвенный пустулезный псориаз Барбера, акродерматит стойкий пустулезный - различные проявления пустулезной фрормы. Некоторые выделяемые ранее клинические разновидности псориаза - веррукозный, или бородавчатый, рупиоидный, географический, гирляндовидный, серпигинозный, точечный или фолликулярный, нумулярный, пятнистый, застарелый, себорейный (себопсориаз) - в настоящее время практически не используют [7-9].

Псориатический артрит является одним из клинических проявлений псориаза, а не его коморбидным состоянием, в связи с чем обсуждение его клинических форм в рамках классификации псориаза представляется обоснованным. Еще в 1973 г. J. M. Moll и V. Wright выделили пять вариантов (субтипов) псориатического артрита [10]. Однако до настоящего времени фрормы псориатического артрита не описывались в клинической классификации псориаза и рассматривались отдельно, что создавало определенные неудобства в практической работе врачей-дерматологов.

С другой стороны, поражения глаз при псориазе (увеит, склерит, эписклерит) необходимо рассматривать именно как коморбидное заболевание, а не «внесуставное проявление псориатического артрита», в связи с чем в классификацию псориаза их не вносят [11].

В большинстве классификаций псориаза не представлена псориатическая ониходистрофия - изменение ногтевых пластинок, наблюдающееся при различных формах заболевания и имеющее достаточно широкий спектр клинических проявлений [12]. Последнее обстоятельство представляется неправильным, так как с современных позиций именно псориатическое поражение ногтевых пластинок рассматривают в качестве одного из предикторов псориатического артрита. С практической точки зрения включение псориатической ониходистрофии в классификацию анализируемого дерматоза позволит врачу-дерматологу проявить настороженность в отношении субклинических проявлений псориатического артрита и выбирать проактивную тактику в отношении диагностики данного клинического проявления псориаза.
Относительно недавно в научной литературе появился новый термин - парадоксальный псориаз, под которым понимают случаи развития псориаза de novo (любая клиническая фрорма псориаза - бляшечная, пустулезная, псориатический артрит) или значимое ухудшение существующих проявлений, изменение морфологии сыпи как проявление нежелательных явлений на фоне проводимой терапии генно-инженерными биологическими препаратами пациентов с иммуновоспалительными заболеваниями: псориазом и псориатическим артритом, ревматоидным артритом, анкилозирующим спондилитом, воспалительными заболеваниями кишечника, ювенильным идиопатическим артритом, SAPHO синдромом, болезнью Бехчета и др. Более половины всех случаев парадоксального псориаза представлены ладонно-подошвенным пустулезом [13-16]. Вместе с тем терапевтическая тактика ведения пациентов с парадоксальным псориазом не имеет каких-либо отличий: назначение лечения соответствует протоколу, который применяется при вульгарном, пустулезном псориазе или псориатическом артрите. В этой связи выделение парадоксального псориаза в отдельную рубрику классификации данного дерматоза нецелесообразно.

По распространенности процесса на коже С.Т. Павлов и О.К. Шапошников выделяли ограниченный (1-2 анатомические области), диффузный, диссеминированный и универсальный псориаз. Подобная характеристика не всегда позволяла судить о площади поражений и тяжести дерматоза. Например, при «ограниченном» изолированном поражении спины (1 анатомическая область) высыпания могли занимать до 10-15\% кожного покрова, а при «распространенном» ладонно-подошвенном псориазе - всего 3-4\%. С внедрением в практическую работу дерматологических индексов (BSA - Body surface area - площадь поверхности кожи, PASI - Psoriasis area and severity index - индекс площади и тяжести псориаза) необходимость в определении распространенности псориаза отпала, а точность оценки тяжести заболевания существенно повысилась [17].

Попытки классисицировать псориаз с учетом возраста начала заболевания (I и II тип), сезонности обострений (зимний, летний, смешанный тип), чувствительности к УФО (УФ-курабельные и УФ-некурабельные формы) оказались неоправданны - различия в клинических проявлениях псориаза у больных с ранним и поздним дебютом не были подтверждены на больших группах, сезонность рецидивов и чувствительность к ультрафиолетовому облучению не являются постоянным признаком и часто изменяются со временем [18, 19].

При анализе различных классификаций псориаза рабочая группа Комитета РОДВК по классификациям в дерматовенерологии не нашла принципиальных различий между ними - все они строятся на клиническом подходе и учитывают различные особенности клинических разновидностей дерматоза и (или) локализации высыпных элементов. Исключение, пожалуй, составляет классификация МКБ-10, которая носит статистический характер, предназначена именно для целей статистического учета и поэтому не может лежать в основе клинических подходов к диагностике и лечению псориаза.

В актуализированных Клинических рекомендациях: Псориаз (2020), разработанных Российским обществом дерматовенерологов и косметологов и одобренных 
научно-практическим советом Минздрава РФ, в разделе 1.5 «Классификация заболевания или состояния (группы заболеваний или состояний)» указано, что в настоящее время принято выделять несколько клинических фрорм псориаза: обыкновенный (вульгарный, бляшечный); себорейный; каплевидный; пустулезный (генерализованный Цумбуша, ладоней и подошв Барбера, акродерматит стойкий гнойный Аллопо); инверсный; псориатическая эритродермия; псориатический артрит (псориаз артропатический) [20]. Однако до сих пор не все дерматологи имеют общее понимание особенностей разных фрорм псориаза, что отражается как на процессе диагностики, так и на подходах в терапии. Именно это делает необходимым разработку, обсуждение и утверждение современной отечественной клинической классификации псориаза с ее последующим использованием в установочных, правовых документах и в практической деятельности специалистов.

После обсуждения различных вариантов классифрикаций псориаза рабочая группа Комитета РОДВК по классификациям в дерматовенерологии считает рациональным ознакомить практических врачей с ответами на некоторые вопросы, которые возникали в процессе работы.

1. Правомерен ли термин «бляшечный» псориаз для обозначения вульгарного псориаза?

Термин «бляшечный» псориаз чаще употребляют наши иностранные коллеги, в России в основном используют термин «вульгарный, или обыкновенный» псориаз, хотя в последнее время при проведении клинических исследований и отечественные дерматологи применяют термин «бляшечный» псориаз. Эти термины являются синонимами, и в предлагаемой нами классификации они указаны оба.

2. Следует ли внести в классифрикацию стадии псориатического процесса в связи с разными подходами в местном лечении?

Стадии развития псориаза (прогрессирующая, стационарная, регрессирующая), безусловно, имеют значение при определении методов наружного лечения заболевания и фототерапии, однако данный материал уже многократно и достаточно изложен в клинических руководствах и учебниках, а повторение его в классификации клинических фоом псориаза излишне.

3. Стоит ли подробно разбирать псориатический артрит в классифрикации псориаза, не вопрос ли это ревматологов?

Учитывая, что дерматовенеролог часто является первым специалистом, который диагностирует дебют псориатического артрита у больного псориазом, а также то, что одной из трудовых функций, входящих в профессиональный стандарт врача-дерматовенеролога, является ведение пациентов с поражениями суставов, целесообразно внести субтипы псориатического артрита в единую классификацию и перечислить другие возможные проявления воспаления опорно-двигательного аппарата: поражение капсул суставов, связок и сухожилий (энтезит), синовиальных оболочек (теносиновит, дактилит) и др.

4. Насколько необходимо включение в классифрикацию аннулярного пустулезного псориаза и герпетифомного импетиго/генерализованного пустулезного псориаза беременных?

Из-за редкости этих клинических форм выделение их в виде самостоятельной рубрики в классификации псориаза нецелесообразно. Вместе с тем специалисты должны знать, что в повседневной клинической практике аннулярный пустулезный псориаз может встречаться в детском возрасте, крайне редко - у взрослых. Характеризуется хроническим доброкачественным течением, кольцевидным расположением инфильтрированных бляшек с пустулами по краю колец [21]. Данная фрорма псориаза не требует назначения массивного лечения, как при генерализованном пустулезном псориазе. Также достаточно редко встречается генерализованный пустулезный псориаз беременных, ранее расцениваемый как герпетиформное импетиго беременных. Заболевание возникает, как правило, в 3-м триместре беременности и является угрожающим состоянием как для матери, так и для плода. Терапия проводится системными противопсориатическими препаратами с учетом показаний и противопоказаний каждого из них, в том числе имеется опыт использования генно-инженерных биологических средств [22, 23].

В результате обсуждения рабочая группа предлагает следующую классификацию псориаза:

1. Вульгарный (бляшечный) псориаз (L40.0) [EA90.0]:

Клинические варианты вульгарного (бляшечного) псориаза:

паплевидный псориаз (L40.4) [EA90.1];

- экссудативный псориаз (L40.8) [EA90.0 или EA90.Z];

инверсный (L40.8 или L40.0) [EA90.52];

п ладонно-подошвенный псориаз (L40.0) [EA90.5Y].

\section{2. Пустулезный псориаз [ЕА90.4]:}

І. Генерализованная фрорма:

генерализованный пустулезный псориаз (L40.1) [EA90.40]

II. Локализованные формы:

п ладонно-подошвенный пустулезный псориаз (L40.3) [ЕA90.42];

шакродерматит стойкий пустулезный (L40.2) [EA90.41].

\section{3. Псориатическая эритродермия (L40.8) [EA90.3].}

\section{4. Псориатическая ониходистрофия (L40.9) [EA90.51].}

\section{5. Псориатический артрит (L40.5 или M07.0-M07.3, M09.0) [FA21]:}

Клинические варианты псориатического артрита:

- асимметричный олигоартрит (L40.59 или M07.3) [FA21];

шимметричный полиартрит (ревматоидоподобный) (L40.59 или M07.3) [FA21];

дистальный межфаланговый артрит (L40.51 или M07.0) [FA21];

псориатический спондилоартрит (L40.53 или M07.2) [FA21.0];

мутилирующий артрит (L40.52) [FA21].

Примечание: в круглых скобках указан шифр по МКБ-10, в квадратных — по МКБ-11.

\section{Комментарии}

Члены рабочей группы Комитета по классификациям РОДВК считают необходимым изложить в комментариях отдельные пояснения к некоторым вариантам псориатического поражения кожи и псориатического поражения опорно-двигательного аппарата, которые 
чаще других вызывают вопросы у практических врачей. Мы старались изложить современное понимание этих вопросов, но не ставили своей задачей дать развернутое описание всей клинической картины или вопросов диагностики.

\section{Себорейный псориаз (L40.0) [EA90.50]}

Развивается у больных себореей, характеризуется локализацией высыпаний на себорейных участках кожи (волосистая часть головы, носогубные и заушные складки, грудь и межлопаточная область). Высыпания слабо инфильтрированы, и их границы менее четкие, чем при обычной форме; пропитанные кожным салом желтоватые псориатические чешуйки удерживаются на поверхности, симулируя картину себорейного дерматита. «Псориатическая триада» воспроизводится плохо. Себорейные бляшки, особенно расположенные в области затылка, могут сопровождаться интенсивным зудом. У больных себорейным псориазом часто обнаруживают нарушения липидного и углеводного обмена. Поражение волосистой части головы проявляется обильным шелушением без отчетливо выраженных воспалительных явлений, напоминая асбестовидный лихен. При отсутствии типичных высыпаний в других локализациях для постановки диагноза следует обращать внимание на состояние ногтевых пластинок, а также учитывать данные о наличии псориаза у родственников больного. Выделение себорейного псориаза в отдельную клиническую форму сочтено нецелесообразным, так как это состояние в принципе относится к вульгарному (бляшечному) псориазу и в отличие от других его вариантов не имеет принципиальных особенностей патогенеза.

\section{Пустулезный псориаз [ЕА90.4]}

Генерализованный пустулезный псориаз (тип Цумбуша) характеризуется острым, подострым или, реже, хроническим течением. Течение тяжелое с лихорадкой, генерализованной лимфооденопатией, недомоганием, разбитостью, лейкоцитозом, повышением СОЭ. На начальном этапе при появлении лихорадки, ознобов важным предиктором появления пустул на коже принято считать возникновение отдельных пустулезных элементов на слизистой оболочке языка, которые в условиях повседневной клинической практики редко диагностируются специалистами [24, 25]. Далее приступообразно на фоне яркой эритемы или типичных псориатических элементов появляются мелкие поверхностные пустулы, сопровождающиеся жжением и болезненностью, расположенные как в зоне бляшек, так и на ранее неизмененной коже. Вначале разбросанные, очаги эритемы с пустулизацией быстро увеличиваются в размерах, сливаются, захватывая обширные участки кожного покрова, в пределах этой эритемы типичные псориатические бляшки перестают быть различимыми. Слившиеся пустулы отслаивают поверхностные слои эпидермиса, формируются т. н. гнойные озера. Может развиваться эритродермия. Часты дистрофические изменения ногтей, поражение суставов (псориатический артрит), иногда почек. Пустулезные высыпания находятся в разной стадии развития. После прекращения их появления состояние больных улучшается, температура снижается. После разрешения стерильных пустул псориатический процесс обычно приобретает свой первоначальный вид. Нередко процесс принимает затяжной характер с периодическими повторениями обострений, с интервалами от нескольких дней до месяцев. Симптомы псориатической триады при пустулезном псориазе не воспроизводятся. В качестве провоцирующих фракторов, способствующих развитию этой формы, отмечают стрессы, инфекции, беременность, гипокальциемию, резкую отмену длительно применяемой системной иммуносупрессивной терапии (системных глюкокортикостероидов, метотрексата и т.д.), прием препаратов лития, пероральных контрацептивов и т.п.

Локализованный пустулезный псориаз (тип Барбера) возникает как при наличии типичных псориатических высыпаний, так и без них, но чаще у пациентов с личной или семейной предысторией псориаза. На ладонях (чаще в области тенара и гипотенара) и подошвах появляется одна или несколько резко очерченных бляшек, в пределах которых имеются многочисленные пустулы 2-5 мм в диаметре. Свежие пустулы - желтого цвета, некоторые из них сливаются, образуя «гнойные озера». Не вскрываясь, пустулы постепенно подсыхают с образованием коричневых корок, другие появляются им на смену. Характерна симметричность очагов поражения. Феномены псориатической триады воспроизводятся с трудом из-за выраженного гиперкератоза. Симптом «стеаринового пятна» псориатической триады не воспроизводится. Провоцирующие фракторы детально не установлены, однако безусловна значимость эндокринных, иммунных, психогенных нарушений, дисфункций вегетососудистой и гепатобилиарной систем.

Акродерматит стойкий гнойный Аллопо проявляется эритематозно-сквамозными и везикуло-пустулезными высыпаниями на дистальных фалангах пальцев. На пораженных участках пальцев отмечаются яркая эритема, отек, множественные пустулы, сливающиеся в «гнойные озера». Дистальные фаланги утолщены, ногтевые пластинки дистрофически изменены. Определение псориатической триады затруднительно и не информативно.

\section{Псориатическая эритродермия (L40.8) [EA90.3]}

Псориатическая эритродермия чаще возникает в результате обострения уже существующего вульгарного псориаза под влиянием раздражающих факторов, нерационального лечения или резкой отмены системной иммуносупрессивной терапии (например, глюкокортикостероидами, метотрексатом или ароматическими ретиноидами). Также эритродермия может развиться первично у здорового человека при слиянии высыпаний быстро прогрессирующего псориаза. Процесс распространяется на весь кожный покров. Кожа становится ярко-красной, отечной, инфильтрированной, местами лихенифицированной, горячей на ощупь, покрывается большим количеством крупных и мелких сухих белых чешуек. Пациентов беспокоит зуд, иногда сильный, жжение и чувство стягивания кожи, болезненность. Нарушается общее состояние пациента: появляются слабость, недомогание, потеря аппетита, температура тела повышается до 38-39 ${ }^{\circ} \mathrm{C}$, увеличиваются лимфатические узлы (в первую очередь паховые и бедренные), снижается потоотделение. При длительном существовании подобного состояния могут выпадать волосы и поражаться ногти. Псориатическая триада не определяется, так как «затушеваны» характерные для заболевания патоморфологические признаки. 
Псориатическую эритродермию следует отличать от состояния универсального псориаза - универсального (почти тотального) поражения кожи сливающимися друг с другом, но остающимися при этом типичными папулами и бляшками вульгарного псориаза. При таком универсальном поражении кожи нет ярко-красной отечности кожи, обычно не наблюдается выраженных нарушений общего состояния, явлений интоксикации и пр., как при псориатической эритродермии.

\section{Псориатическая ониходистрофия (L40.9) [EA90.51]}

Псориатическая ониходистрофия является важным симптомом, так как может быть предиктором развития псориатического артрита [26], и знание этого важно для практических врачей. Выделяют различные варианты поражения ногтевого ложа (симптом «масляного пятна», подногтевой гиперкератоз, онихолизис, продольные геморрагии (в виде занозы) и поражения ногтевого матрикса (точечные вдавления - симптом «наперстка», лейконихии, крошение - разрушение ногтя, красные пятна в области ногтевой лунки, поперечные борозды - линии Бо, онихомадезис отторжение проксимального края ногтя, онихорексис, продольные гребни.

\section{Псориаз артропатический/Псориатический артрит (L40.5 или M07.0-M07.3, M09.0) [FA21]}

Термин «артропатия» исторически возник и применялся для описания изменений суставов, связанных с нарушением трофики (напр. табетическая артропатия). Поражение суставов при псориазе носит воспалительный характер, именно поэтому верным является использование термина «артрит». Однако на протяжении многих лет параллельно продолжают употреблять оба термина - псориатическая артропатия и псориатический артрит. Псориатический артрит - хроническое воспалительное поражение суставов, позвоночника и энтезисов, которое может развиваться у больных псориазом. Согласно современной классификации спондилоартритов, псориатический артрит относят к подгруппе периферических спондилоартритов, при которых наблюдаются, главным образом, воспаление периферических суставов (артрит), пальцев кистей и стоп (дактилит), энтезисов (энтезит), теносиновиита (воспаление сухожилий сгибателей и/или разгибателей пальцев кистей и стоп), а также может наблюдаться воспаление в аксиальных структурах - телах позвонков (спондилит) и илеосакральных сочленениях (сакроилиит) в разных сочетаниях.
Асимметричный олигоартрит - обычно асимметричное поражение коленных, лучезапястных, голеностопных, локтевых, а также межфаланговых суставов кистей и стоп, при этом общее число воспаленных суставов не превышает 4.

Симметричный полиартрит (ревматоидоподобный) - симметричное вовлечение парных суставов как при ревматоидном артрите.

Дистальный межфаланговый артрит - преимущественное поражение дистальных межфаланговых суставов кистей кистей и/или стоп. Изолированное поражение этих суставов наблюдается у $5 \%$ больных псориатическим артритом. При других вариантах псориатического артрита дистальные межфраланговые суставы также могут поражаться.

Псориатический спондилоартрит - воспалительное поражение позвоночника как при анкилозирующем спондилите, часто сочетается с периферическим артритом.

Мутилирующий артрит - распространенная резорбция суставных поверхностей (остеолиз) с укорочением пальцев кистей и/или стоп с деформацией, укорочением, разнонаправленными подвывихами пальцев конечностей. Локальный остеолиз суставных поверхностей может развиваться при всех клинических вариантах псориатического артрита.

Необходимость создания обновленной единой классификации псориаза обусловлена желанием унифицировать подходы к пониманию и оценке тех или иных клинических проявлений дерматоза, что позволит специалистам вести разговор о диагнозе данного заболевания на одном языке. Настоящий консенсусный документ отражает современный взгляд на классификацию псориаза в России и в мире и вместе с тем предполагает, что его содержание должно регулярно обсуждаться и обновляться.

\section{Заключение}

В результате обсуждения различных вариантов классификаций псориаза рабочая группа Комитета РОДВК по классификациям в дерматовенерологии предлагает использовать в клинической работе врачей-дерматовенерологов, в учебных и научных целях — при обучении в медицинских образовательных учреждениях высшего образования, при обучении по специальности «дерматовенерология» (код ОКСО 3.31.08.32), при планировании и проведении научных исследований, при публикациях в научных медицинских журналах, при разработке Клинических рекомендаций - «Классификацию псориаза», изложенную в этой статье.

\section{Литература/References}

1. Parisi R, Symmons DP, Griffiths CE, Ashcroft DM; Identification and Management of Psoriasis and Associated ComorbidiTy (IMPACT) project team. Global epidemiology of psoriasis: a systematic review of incidence and prevalence. J Invest Dermatol. 2013;133(2):377-385. doi: 10.1038/jid.2012.339

2. Raychaudhuri SK, Maverakis E, Raychaudhuri SP. Diagnosis and classification of psoriasis. Autoimmun Rev. 2014;13(4-5):490-495. doi: 10.1016/j.autrev.2014.01.008.
3. Скрипкин Ю.К. Кожные и венерические болезни. Руководство / Под ред. Ю.К. Скрипкина. М.: Медицина; 1995. Т. 2; 571 с. [Skripkin YUK. Kozhnye i venericheskie bolezni. Rukovodstvo / Pod redakciej Yu.K. Skripkina. Moscow: Medicina; 1995. T. 2; p. 571 (In Russ.)]

4. Козин В.М. Псориаз (Вопросы патогенеза, клиники, терапии). Витебск; 2007. 227 с. [Kozin VM. Psoriaz (Voprosy patogeneza, kliniki, terapii) Vitebsk; 2007. p. 227 (In Russ.)] 
5. Вульф К., Джонсон Р., Сюрмонд Д. Дерматология по Томасу Фицпатрику М.: Практика; 2007. 1248 с. [Vul'f K, Dzhonson R, Syurmond D. Dermatologiya po Tomasu Ficpatriku. Moscow: Praktika; 2007. p. 1248 (In Russ.)]

6. Хебиф Т.П., Кэмпбелл-мл. Д.Л., Чэпмэн М.Ш., Динулос Д.Г.Х., Цуг К.Э. Кожные болезни. Диагностика и лечение М.: МЕДпресс-информ. 2016. 700 c. [Hebif TP, Kempbell-ml. DL, CHepmen MSH, Dinulos DGH, Cug KE. Kozhnye bolezni. Diagnostika i lechenie. Moscow: MEDpress-inform. 2016. p. 700 (In Russ.)]

7. Машкиллейсон Л.Н. Частная дерматология. М.: Медицина; 1965. 522 с. [Mashkillejson LN CHastnaya dermatologiya. Moscow: Medicina; 1965. p. 522 (In Russ.)]

8. Павлов С.Т., Шапошников О.К., Самцов В.И., Ильин И.И. Кожные и венерические болезни / Под ред. О.К. Шапошникова. М.; 1985. 368 с. [Pavlov ST, Shaposhnikov OK, Samtsov VI, Il'in II. Kozhnye i venericheskie bolezni / Pod red. 0. K. Shaposhnikova. Moscow; 1985. p. 368 (In Russ.)]

9. Довжанский С.И., Утц С.Р. Псориаз или псориатическая болезнь. Саратов: Изд-во Саратовского ун-та; 1992. 176 с. [Dovzhanskij SI, Utc SR. Psoriaz ili psoriaticheskaya bolezn'. Saratov: Izd-vo Saratovskogo universiteta; 1992. p. 176 (In Russ.)]

10. Moll JM, Wright V. Psoriatic arthritis. Semin Arthritis Rheum. 1973;3(1):55-78. doi: 10.1016/0049-0172(73)90035-8

11. Burden-Teh E, Murphy R. Psoriasis and uveitis--should we be asking about eye symptoms? $\mathrm{Br} J$ Dermatol. 2014;170(3):756-757. doi: 10.1111/bjd.12731

12. Schons KR, Knob CF, Murussi N, Beber AA, Neumaier W, Monticielo OA. Nail psoriasis: a review of the literature. An Bras Dermatol. 2014;89(2):312-317. doi: 10.1590/abd1806-4841.20142633

13. Baeten D, Kruithof E, Van den Bosch F, Van den Bossche N, Herssens A, Mielants $H$, et al. Systematic safety follow up in a cohort of 107 patients with spondyloarthropathy treated with infliximab: a new perspective on the role of host defence in the pathogenesis of the disease? Ann Rheum Dis 2003;62:829-834. doi: 10.1136/ard.62.9.829

14. Collamer AN, Battafarano DF. Psoriatic skin lesions induced by tumor necrosis factor antagonist therapy: clinical features and possible immunopathogenesis. Semin Arthritis Rheum. 2010;40(3):233-240. doi: 10.1016/j.semarthrit.2010.04.003

15. Bae JM, Kwon HS, Kim GM, Park KS, Kim KJ. Paradoxical psoriasis following anti-TNF therapy in ankylosing spondylitis: A populationbased cohort study. J Allergy Clin Immunol. 2018;142(3):1001-1003.e2. doi: 10.1016/j.jaci.2018.05.015
16. Montolio Chiva L, Martínez Ferrer À, Mateu PuchadesA, Campos Fernández C, Narváez Garcia J, Alegre Sancho JJ. Psoriasis inducida porterapia biológica. Reumatol Clin. 2020. doi: 10.1016/j.reuma.2019.12.005

17. Кубанов А.А., Карамова А.Э., Знаменская Л.Ф., Чикин В.В., Кондрашова В.В. Индекс PASI (Psoriasis Area and Severity Index) в оценке клинических проявлений псориаза. Вестник дерматологии и венерологии. 2016;4:33-38. [Kubanov AA, Karamova AE, Znamenskaya LF, CHikin VV, Kondrashova VV. PASI (Psoriasis Area and Severity Index) in the evaluation of the clinical manifestatations of psoriasis. Vestnik dermatologii i venerologii. 2016;4:33-38 (In Russ.)]

18. Christophers E, Sterry W. Psoriasis. In: Fitzpatrick TB, Eisen AZ, Wolff $K$, Freedberg IM, Austen KF (eds). Dermatology in general medicine. McGraw-Hill, New York; 1993. p. 489-514.

19. Matthews D, Fry L, Powles A, Weber J, McCarthy M, Fisher E, et al. Evidence that a locus for familial psoriasis maps to chromosome $4 \mathrm{q}$. Nat Genet. 1996;14(2):231-233. doi: 10.1038/ng1096-231

20. Клинические рекомендации: Псориаз (2020) [Clinical practice guidelines: Psoriasis (2020)] https://www.cnikvi.ru/docs/clinic_recs/ klinicheskie-rekomendatsii-2019-2020/.

21. Shah M, Al Aboud DM, Crane JS, Kumar S. Pustular Psoriasis. 2021. In: StatPearls [Internet]. Treasure Island (FL): StatPearls Publishing; 2021.

22. Danesh M, Pomeranz MK, McMeniman E, Murase JE. Dermatoses of pregnancy: Nomenclature, misnomers, and myths. Clin Dermatol. 2016;34(3):314-319. doi: 10.1016/j.clindermatol.2016.02.002

23. Trivedi MK, Vaughn AR, Murase JE. Pustular psoriasis of pregnancy: current perspectives. International Journal of Women's Health. 2018;10:109-115.

24. Рациональная фармакотерапия заболеваний кожи и инфекций, передаваемых половым путем / Под ред. А.В. Самцова и Е.В. Соколовского. М.: изд-во Литтерра, 2021. [Rational pharmacotherapy of skin diseases and sexually transmitted infections / Ed. By AV Samtsov and EV Sokolovskiy. Moscow: Litterra Publishing House. 2021 (In Russ.)]

25. Tomb R, Hajj H, Nehme E. Manifestations buccales du psoriasis (Oral lesions in psoriasis). Ann Dermatol Venereol. 2010;137(11):695-702. French. doi: 10.1016/j.annder.2010.08.006

26. Villani AP, Rouzaud $M$, Sevrain M, Barnetche T, Paul C, Richard MA, at al. Symptoms dermatologists should look for in daily practice to improve detection of psoriatic arthritis in psoriasis patients: an expert group consensus. J Eur Acad Dermatol Venereol. 2014;28 Suppl 5:27-32. doi: 10.1111/jdv.12563

Участие авторов: обоснование рукописи, поисково-аналитическая работа, анализ литературных данных и их интерпретация, написание статьи, одобрение рукописи и направление рукописи на публикацию - все соавторы статьи в равной степени.

Authors' participation: justification of the manuscript, literature analysis and interpretation, writing an article, approval of the submission of the manuscript for publication — all co-authors of the article equally. 


\section{Информация об авторах}

*Карамова Арфеня Эдуардовна - к.м.н., доцент; адрес: Россия, 107076, Москва, улица Короленко, д. 3, стр. 6; ORCID iD: http://orcid.org/0000-0003-3805-8489; eLibrary SPIN: 3604-6491; e-mail: karamova@cnikvi.ru

Олисова Ольга Юрьевна - Д.м.н., професcop; ORCID iD: https://orcid.org/0000-0003-2482-1754; eLibrary SPIN: 2500-7989; e-mail: olisovaolga@mail.ru

Бакулев Андрей Леонидович - д.м.н., професcop; ORCID iD: https://orcid.org/0000-0002-1450-4942; eLibrary SPIN: 6708-7386; e-mail: al_ba05@mail.ru

Кохан Муза Михайловна - д.м.Н., просреccop; ORCID iD: https://orcid.org/0000-0001-6353-6644; eLibrary SPIN: 3470-9306; e-mail: mkokhan@yandex.ru

Хайрутдинов Владислав Ринатович - д.м.Н., доцент; ORCID iD: https://orcid.org/0000-0002-0387-5481; eLibrary SPIN: 4417-9117; e-mail: haric03@list.ru

Соколовский Евгений Владиславович - д.м.н., професcop; ORCID iD: https://orcid.org/0000-0001-7610-6061, eLibrary SPIN: 6807-7137, e-mail: s40@mail.ru

Хобейш Марианна Михайловна - К.м.Н., доцент; ORCID iD: https://orcid.org/0000-0001-8670-7223; eLibrary SPIN: 4377-8101; e-mail: mkhobeysh@yandex.ru

\section{Information about the authors}

*Arfenya E. Karamova - MD, Cand. Sci. (Med.); assistant professor; address: 3 bldg 6, Korolenko street, 107076, Moscow, Russia; ORCID iD: https://orcid.org/0000-0002-9688-2727; eLibrary SPIN: 3385-4723; e-mail: karamova@cnikvi.ru

Olga Yu. Olisova - MD, Dr. Sci. (Med.), Professor; ORCID iD: https://orcid.org/0000-0003-2482-1754; eLibrary SPIN: 2500-7989; e-mail: olisovaolga@mail.ru

Andrey L. Bakulev - Dr. Sci. (Med.), Professor; ORCID iD: https://orcid.org/0000-0002-1450-4942; eLibrary SPIN: 6708-7386; e-mail: al_ba05@mail.ru

Muza M. Kokhan - MD, Dr. Sci. (Med.), Professor; ORCID iD: https://orcid.org/0000-0001-6353-6644; eLibrary SPIN: 3470-9306; e-mail: mkokhan@yandex.ru

Vladislav R. Khairutdinov - MD, Dr. Sci. (Med.), assistant professor; ORCID iD: https://orcid.org/0000-0002-0387-5481; eLibrary SPIN: 4417-9117; e-mail: haric03@list.ru

Evgeny V. Sokolovskiy — MD, Dr. Sci. (Med.), Professor; ORCID iD: https://orcid.org/0000-0001-7610-6061, eLibrary SPIN: 6807-7137, e-mail: s40@mail.ru

Marianna M. Khobeych — MD, Cand. Sci. (Med.), assistant professor; ORCID iD: https://orcid.org/0000-0001-8670-7223; eLibrary SPIN: 4377-8101; e-mail: mkhobeysh@yandex.ru

Статья поступила в редакцию: 09.08.2021

Принята к публикации: 20.08.2021

Дата публикации: 15.10 .2021
Submitted: 09.08 .2021

Accepted: 20.08.2021

Published: 15.10 .2021 